\title{
Variant Rett syndrome in a girl with a pericentric X-chromosome inversion leading to epigenetic changes and overexpression of the MECP2 gene
}

\author{
José Pedro Vieira ${ }^{\mathrm{a}, 1}$, Fátima Lopes ${ }^{\mathrm{b}, \mathrm{c}, 1}$, Anabela Silva-Fernandes ${ }^{\mathrm{b}, \mathrm{c}}$, Maria Vânia Sousa ${ }^{\mathrm{a}}$, \\ Sofia Moura ${ }^{\text {b,c }}$, Susana Sousa ${ }^{\text {b,c }}$, Bruno M. Costa ${ }^{\text {b,c }}$, Mafalda Barbosa ${ }^{d, e}$, Bauke Ylstra ${ }^{\text {, }}$, \\ Teresa Temudo $^{\mathrm{g}}$, Teresa Lourenço ${ }^{\mathrm{a}}$, Patrícia Maciel ${ }^{\mathrm{b}, \mathrm{c}, *}$ \\ a Neurology Department, Hospital Dona Estefânia, Centro Hospitalar de Lisboa Central, Portugal \\ ${ }^{\mathrm{b}}$ Life and Health Sciences Research Institute (ICVS), School of Health Sciences, University of Minho, Braga, Portugal \\ ' ICVS/3B's - PT Government Associate Laboratory, Braga/Guimarães, Portugal \\ ${ }^{\mathrm{d}}$ Department of Genetics and Genomic Sciences, The Mindich Child Health E' Development Institute, The Seaver Autism Center for Research and Treatment, \\ Icahn School of Medicine at Mount Sinai, NY, USA \\ e Instituto Gulbenkian de Ciência, Oeiras, Portugal \\ f Department of Pathology, VU University Medical Center, Amsterdam, The Netherlands \\ ${ }^{g}$ Neuropediatrics Department, Centro Hospitalar do Porto, Portugal
}

\section{A R T I C L E I N F O}

\section{Article history:}

Received 18 May 2015

Received in revised form 3 July 2015

Accepted 15 July 2015

Available online 10 August 2015

\section{Keywords:}

Epigenetics

Epilepsy

Intellectual disability

Neurodevelopment

\begin{abstract}
A B S T R A C T
Rett syndrome is a neurodevelopmental disorder caused by mutations in the MECP2 gene. We investigated the genetic basis of disease in a female patient with a Rett-like clinical. Karyotype analysis revealed a pericentric inversion in the $X$ chromosome $-46, X, \operatorname{inv}(X)(p 22.1 q 28)$, with breakpoints in the cytobands where the MECP2 and CDKL5 genes are located. FISH analysis revealed that the MECP2 gene is not dislocated by the inversion. However, and in spite of a balanced pattern of X inactivation, this patient displayed hypomethylation and an overexpression of the MECP2 gene at the mRNA level in the lymphocytes (mean fold change: $2.55 \pm 0.38$ ) in comparison to a group of control individuals; the expression of the CDKL5 gene was similar to that of controls (mean fold change: $0.98 \pm 0.10$ ). No gains or losses were detected in the breakpoint regions encompassing known or suspected transcription regulatory elements. We propose that the de-regulation of $M E C P 2$ expression in this patient may be due to alterations in long-range genomic interactions caused by the inversion and hypothesize that this type of epigenetic de-regulation of the MECP2 may be present in other RTT-like patients.
\end{abstract}

(c) 2015 Elsevier Ltd. All rights reserved.

\section{Introduction}

Rett syndrome (RTT) is a neurodevelopmental disorder characterized by an early regression followed by stagnation in growth and development, leading to mental retardation, stereotypies and motor apraxia that may be associated with epilepsy and with dysautonomic features, including disturbed breathing, sleep and gastrointestinal motility (Hagberg et al., 1983; Rett, 1966). RTT is caused by mutations in the MECP2 gene, encoding a methyl-CpG

\footnotetext{
* Corresponding author at: Life and Health Sciences Research Institute (ICVS), School of Health Sciences, University of Minho, 4710-057 Braga, Portugal. Tele/Fax: +351 253 604824/20

E-mail address: pmaciel@ecsaude.uminho.pt (P. Maciel).

1 Both authors contributed equally to this work.
}

binding protein thought to be involved in transcriptional regulation (Amir et al., 1999; Hoffbuhr et al., 2001; Philippe et al., 2006). Mutations in this gene are present in more than $90 \%$ of patients that fulfill the diagnostic criteria, and with lesser frequency in patients with so-called variant forms of the disease, that do not comply with all these criteria (Amir et al., 1999; Hoffbuhr et al., 2001; Philippe et al., 2006).

The most frequent mutations in MECP2 are point mutations, small insertions or deletions. The genotype of patients without one of these mutations has also been investigated and some cases with gross rearrangements involving the MECP2 gene were found, usually large deletions. In boys, $M E C P 2$ duplication is the rare cause of a severe encephalopathy with recurrent infections, severe mental retardation, microcephaly and epilepsy (Ramocki et al., 2009; Van Esch et al., 2005). MECP2 duplication has also been described in a 
girl with a preserved-speech variant of RTT and in another with nonspecific mental retardation (Ariani et al., 2004; Makrythanasis et al., 2010). Recently Bijlsma et al. reviewed MECP2 duplication in eleven females; five were from their study and six had been previously reported. Intellectual disability was a prominent feature while hand stereotypies, epilepsy, dysmorphism and recurrent infections were less frequent (Bijlsma et al., 2012). Overexpression of normal MeCP2 has also been shown to cause a progressive neurological disorder in a mouse model, showing that the nervous system requires a very precise dosage of this protein for proper functioning (Collins et al., 2004).

Here, we describe a patient with a RTT-like clinical presentation in whom we found no mutations in the MECP2 gene by direct sequencing, nor changes in exon dosage. Karyotype analysis, however, revealed a pericentric inversion in the $\mathrm{X}$ chromosome $46, X, \operatorname{inv}(X)(p 22.1 q 28)$. This inversion is accompanied by epigenetic changes in the form of decreased DNA methylation levels within the $5^{\prime}$ regulatory region of $M E C P 2$ gene, and led to a significantly increased expression of the gene, in spite of its normal dosage, through a mechanism that may involve relatively distant regions of the $\mathrm{X}$ chromosome.

\section{Materials and methods}

\subsection{Patient assessment}

The proband was ascertained and assessed through the Hospital Dona Estefânia (Centro Hospitalar de Lisboa Central) and MECP2 study was requested at the Molecular Diagnostic Service at Life and Health Sciences Research Institute (ICVS) - School of Health Sciences, University of Minho, Braga, Portugal. Informed consent was obtained from the child's parents for blood sampling and genetic analyses. Genomic DNA was extracted from peripheral blood using the Puregene DNA isolation kit (Gentra, Minneapolis, MN).

\subsection{MECP2 mutation detection}

The coding region and exon-intron boundaries of the MECP2 gene were amplified by PCR and sequenced on an automated DNAsequencer (ABI-3130 Genetic Analyzer, Applied Biosystems, Life technologies).

Copy-number analysis of the MECP2 gene was performed by multiplex ligation-dependent probe amplification (MLPA) (MRCHolland, Amsterdam, Netherlands) using SALSA P015 kit and quantitative PCR analysis (qPCR). For MLPA, PCR reactions were carried out using C1000 - Thermal Cycler (BioRad) thermocycler according to the manufacturer's instructions. Products were separated in a 3130 Genetic Analyzer (Applied Biosystems, Foster City, CA, USA) using ROX-500 as internal pattern. The data was analyzed for copy-number differences with Coffalyser software (MRC-Holland, Amsterdam, Netherlands). Primers for qPCR were designed using Primer3Plus software (http://www. bioinformatics.nl/cgi-bin/primer3plus/primer3plus.cgi) and taking into account standard recommendations for qPCR primer development (Jovanovic et al., 2003). Four sets of primers were designed for the MECP2 gene (ENSG00000169057) within the coding region of exon one, two and three and in the $3^{\prime} \mathrm{UTR}$ non-coding region of exon four. The reference genes used were SDC4 (ENSG00000124145) and ZNF80 (ENSG00000174255) localized in the 20q12-q13 and 3p12 regions, respectively. qPCR reactions were carried out in a 7500FAST Real Time PCR machine (Applied Biosystems, Foster City, CA, USA) using Power SYBR Green ${ }^{\circledR}$ (Applied Biosystems). The specificity of each of the reactions was verified by the generation of a melting curve for each of the amplified fragments. The primer efficiency was calculated by the generation of a standard curve fitting the accepted normal efficiency percentage. Quantification was performed as described elsewhere (Hoebeeck et al., 2005). Ct values obtained for each test were analyzed in DataAssist ${ }^{\mathrm{TM}}$ software (Applied Biosystems, Foster City, CA, USA).

\subsection{X chromosome inactivation}

The X-inactivation assay (XCI) was carried out by analysis of the HUMARA (human androgen receptor) locus, which is a highly polymorphic CAG repeat with a very near Hhal enzyme restriction site, according to the described protocol (Jovanovic et al., 2003). The products were separated on an automated DNA-sequencer (ABI3130 Genetic Analyzer, Applied Biosystems, Life technologies) the allele peak height serving as the semi-quantitative measure of the amount of PCR product amplified from each allele. The samples were defined as having a deviated $\mathrm{XCI}$ pattern if they presented a corrected allele ratio out of the $0.33-3$ range.

\subsection{Conventional karyotyping and FISH}

Standard karyotpe analysis was performed using cells cultured from peripheral blood leukocytes, and FISH analysis was undertaken using two distinct probes covering the Xq28 region: RP4-671D9 (153286964-153386210) and RP11-617G06 (153110141-153283527) (BlueGnome, UK).

\subsection{Molecular karyotyping}

The aCGH analysis was performed on a human genome CGH Agilent $180 \mathrm{~K}$ custom array designed by the Low Lands Consortium (LLC, Dr. Klas Kok) in order to be used in the analysis of children with ID/DD (AMADID:023363; Agilent, Santa Clara, CA). DNA labeling was performed using the ENZO Labeling Kit for Oligo Arrays (Enzo Life Sciences, Inc.). As reference DNA we used Kreatechís MegaPoll Reference DNA (Kreatech Diagnostics). Arrays were then hybridized using the Agilent SurePint G3Human CGH Microarray Kit. Data was extracted with the Agilent Feature Extraction (FE) Software v10.5 using default settings for CGH hybridizations. Image analysis was performed using the across-array methodology described previously (Buffart et al., 2008). CGH data was analyzed using Nexus Copy Number 6.0 software with FASST2 Segmentation algorithm. The custom $1 \mathrm{M}$ Agilent array was designed using the eArray web tool (https://earray.chem.agilent.com/earray/). The maximal amount of probes available was selected for the breakpoint regions (Xq22.1 and Xq28). DNA labeling, hybridization and data extraction were performed in the same way as for aCGH $180 \mathrm{~K}$ (described above). CGH data was analyzed using Nexus Copy Number 6.0 software with the FASST2 Segmentation algorithm.

\subsection{MRNA expression analysis}

Total RNA was isolated from leucocytes using TRIZOL (Invitrogen, Calrsbad, CA, USA) according to the manufacturer's protocol. First-strand cDNA, synthesized using iScript ${ }^{\mathrm{TM}}$ cDNA Synthesis Kit (Bio-rad), was amplified by quantitative reverse-transcriptase PCR (qRT-PCR) using QuantiTect SYBR Green PCR Kit (Quiagen). Human MECP2, CDKL5 and HPRT primers were used for relative quantification analysis. MECP2 (Forward: 5'-GGCGCTCCATCATCCGTGAC-3'; Reverse: 5'-CTGGGGATTGATCAAATACACAT-3'), CDKL5 (Forward: 5'-CATTCACTGTCTGCACCTCAC-3'; Reverse: $5^{\prime}$-GTTCTCCAGGTCGGGGTGAC-3') and HPRT (Forward: 5'-CTAATTATGGACAGGGACTGAACG-3'; Reverse: 5'CAGTCATAGGAATGGATCTATCA-3'). The expression levels of the genes were normalized to the HPRT gene and relative quantification was used to determine the fold change difference between MECP2, CDKL5 and HPRT, using the DDCT method, as described before (Pfaffl, 2001). The comparison between the case study 
$(n=1)$ and controls $(n=6)$ is presented, with the respective $t$-test analysis for replicate 1 . This difference was reproduced for the three replicates.

\subsection{Methylation analysis}

For epigenetic analysis the EpiTect Methyl II PCR Primer Assay for Human MECP2 was used where a region of the CpG island 106 (ChrX: 153362568-153363473) was assessed (CpG Island 115358) EPHS115358-1A (Quiagen ${ }^{\circledR}$ ) in the index case, mother and 4 healthy female controls. Briefly, $250 \mathrm{ng}$ of DNA from each sample was digested for $6 \mathrm{~h}$ at $37^{\circ} \mathrm{C}$ degrees. The samples were them amplified by real time PCR using the kit specific MECP2 primers (EPHS115358-1A) with $\mathrm{RT}^{2}$ qPCR SYBR Green ROX master mix in a 7500-FAST Real Time PCR machine (Applied Biosystems, Foster City, CA, USA). Ct values obtained for each sample were analyzed accordingly with the manufacturer's instructions in order to obtain the gene methylation status, as the percentage of unmethylated (UM) and methylated (M) DNA in the input genomic sequence. A $t$-test analysis was performed for the unmethylated DNA in replicate 1 of the assay where the case study $(n=1)$ is compared with the controls $(n=4)$. This difference was reproduced for the three replicates.

\section{Results}

\subsection{Clinical description}

The patient is the second child of healthy, non-consanguineous parents and has no family history of Rett syndrome, intellectual disability or epilepsy. Gestation was uneventful. Delivery, at 39 weeks, was complicated by a difficult forceps extraction. Apgar scores were 8 at $1 \mathrm{~min}$ and 10 at $5 \mathrm{~min}$. Birth weight was $3755 \mathrm{~g}$ ( 75 th centile), length $50 \mathrm{~cm}$ (50th centile) and head circumference $35.5 \mathrm{~cm}$ (75th centile). A brain computed tomography (CT) showed a parietal skull fracture and a small underlying epidural hematoma without parenchymatous brain lesions. In the first days, she remained clinically well, and a control CT scan showed total resolution of the hematoma. The child was first seen by us when she was forty days old, after a brief left-sided clonic partial motor seizure. The neurologic examination was normal. Electroencephalogram (EEG) showed focal paroxysmal activity. CT scan and magnetic resonance imaging (MRI) were normal. Phenobarbital was introduced and up to five months she experienced a few more seizures with a similar pattern. Subsequently she remained asymptomatic. The EEG, repeated at five months, was normal. At this time, however, psychomotor development was clearly in the delayed range. The patient had axial hypotonia and her hands infrequently reached the midline. At nine months she did not sit without support, was unable to reach out and pick objects and her lower limbs were slightly spastic. From twelve months on, RTT-like hand stereotypies appeared and became progressively more frequent. She did not acquire at this time any expressive or comprehensive language and did not point to objects. In the period between four and eighteen months head circumference went from the 75th centile to slightly below the 5th centile. Formal developmental evaluation was performed using the Ruth Griffiths scale at the age of four (45 months), revealing a mental age of 15 months and a Global Developmental Quotient of $34 \%$.

At the age of six to seven she was walking with minimal support, hand movements were more coordinated and intentional, she held a pen and scratched, was able to point to some figures in a book and to say six to eight simple words. Currently, at the age of ten, her vocabulary is still limited to eight words, fine and gross motor skills remain at the same level and RTT-like hand stereotypies are still present, although less frequently than before.
Teeth grinding is frequent. Hyperpnea, apnea, insomnia, unprovoked laughing/screaming and autistic features were not reported by the parents. There is no history of recurrent and/or severe infectious diseases. Recently, epilepsy relapsed with brief hypomotor seizures that were controlled with valproate and oxcarbazepine. EEG reveals posterior temporal spikes.

The child is generally happy, smiles quite often and has good visual interaction. She has a divergent strabismus, misalignment and deformity of the teeth, a slight dorsolumbar scoliosis and no dysmorphic features. Her feet are often cold and pale. Neurologic examination is remarkable for the microcephaly, expressionless face suggesting an extrapyramidal hypokinetic disorder, Rett-like hand movements, spastic hypertonia of lower limbs, dyspraxic gait and brisk reflexes with flexor plantar responses.

\subsection{MECP2 mutation analysis and karyotyping}

We found no variants in the coding region and intron-exon boundaries of this gene by direct Sanger sequencing, nor changes in exon dosage by MLPA and quantitative PCR analysis (qPCR) for the 4 exons. Karyotype analysis in cells cultured from peripheral blood leukocytes, however, revealed a pericentric inversion in the $\mathrm{X}$ chromosome $46, \mathrm{X}, \operatorname{inv}(\mathrm{X})(\mathrm{p} 22.1 \mathrm{q} 28)$ in the patient, which was not present in the mother or father (Fig. $1 \mathrm{~A})$. Of notice, the $M E C P 2$ gene is located in cytoband $\mathrm{Xq} 28$, and the CDKL5 gene in Xp22.1. We then performed FISH to test the hypothesis that the pericentric inversion could have displaced the MECP2 coding sequence or its nearby regulatory regions. We used two probes, one (RP4-671D9) covering the MECP2 gene and $22998 \mathrm{bp}$ of its $5^{\prime}$ region, and the second (RP11-G17G06) covering $173386 \mathrm{bp}$ of $3^{\prime}$ downstream region of the MECP2 gene (see Fig. 1, panel B and $\mathrm{C}$ ). The analysis, however, revealed that the MECP2 gene 5', exonic, and $3^{\prime}$ regions had not been separated by the inversion. These results place the breakpoint at Xq28 more proximally than the location of the RP11-617G06 probe (153110141-153283527, hg19 coordinates), meaning that the breakpoint is not occurring within a distance of $176.883 \mathrm{~Kb}$ downstream the $3^{\prime}$ UTR of the MECP2 gene. In order to clarify if the inversion lead to any loss or gain in the breakpoints we undertook aCGH analysis on a human genome CGH Agilent $180 \mathrm{~K}$ custom array (Buffart et al., 2008) and on a high-resolution custom 1 M Agilent array designed so that the maximal amount of Agilent probes available was selected for the breakpoint regions (Xp22.1 and Xq28 where the CDKL5 and MECP2 genes are located, respectively) and at the citobands 14q12 (where the FOXG1 gene is located). No significant CNVs were found in these regions in both analyses.

\subsection{MECP2 $m$ RNA expression and methylation status}

We then investigated by qRT-PCR the expression levels of the MECP2 (located at Xq28) and CDKL5 (located at Xp22) genes. Intriguingly, the patient displayed an overexpression of the MECP2 gene at the mRNA level in the lymphocytes (mean fold change for the three replicates: $2.55 \pm 0.38$ ), in comparison to a group of 6 control female individuals; in contrast, the expression of the CDKL5 gene was similar to that of controls (mean fold change for the three replicates: $0.98 \pm 0.10$ ) (Fig. $2 \mathrm{~A}$ ). The X-inactivation assay $(\mathrm{XCI})$, carried out by analysis of the HUMARA locus (Jovanovic et al., 2003), showed that the patient had a balanced pattern of $\mathrm{X}$ inactivation, with a ratio of $1 / 1$. To further explore the mechanism leading to the overexpression of $M E C P 2$, we assessed the methylation status of a portion of the $\mathrm{CpG}$ island located in the $5^{\prime}$-regulatory region of the MECP2 using the EpiTect ${ }^{\circledR}$ Methyl II PCR Assay (Quiagen ${ }^{\circledR}$ ). These analyses showed decreased levels of 
A

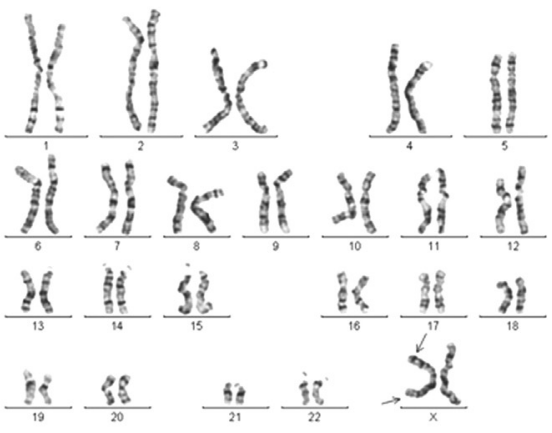

C

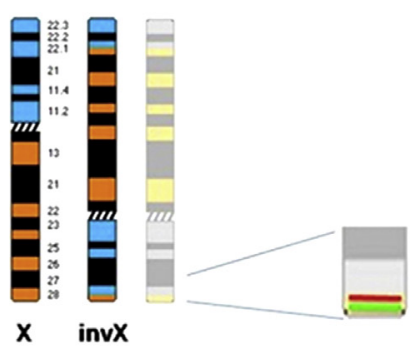

B

Centromer

Telomere
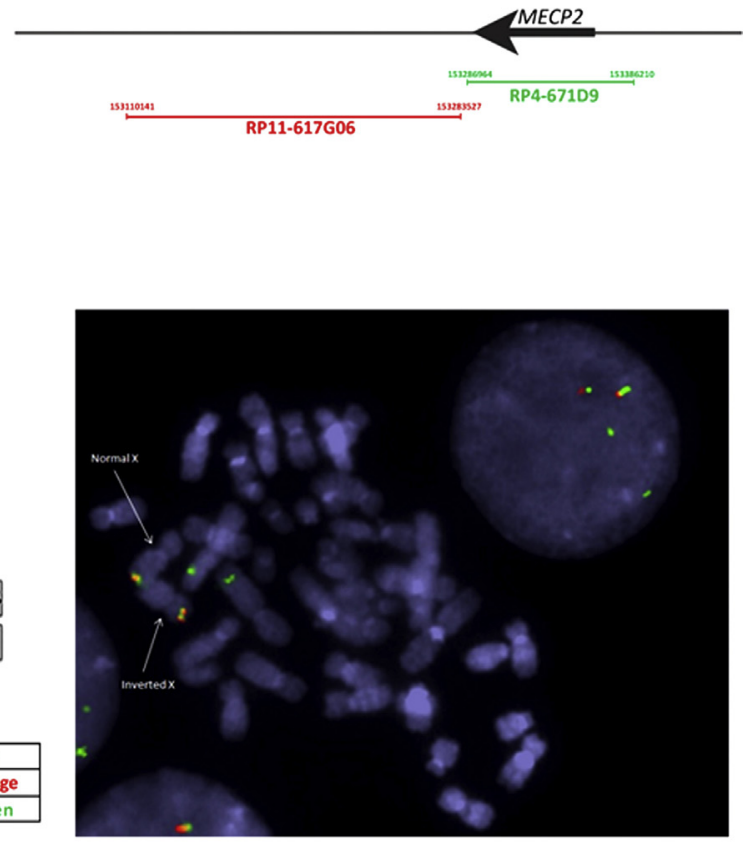

$\mathbf{E}$

Intemational RP11-617G06 RP4-671D9

\begin{tabular}{|c|c|c|c|c|}
\hline Chr. Band & Start & End & Fluorocrom \\
\hline & Xq28 & 153110141 & 153283527 & SpectnumOrange \\
\hline & $X q 28$ & 153286964 & 153386210 & SpectrumGreen \\
\hline
\end{tabular}

D

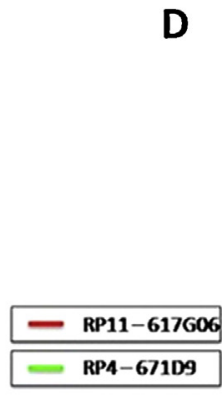

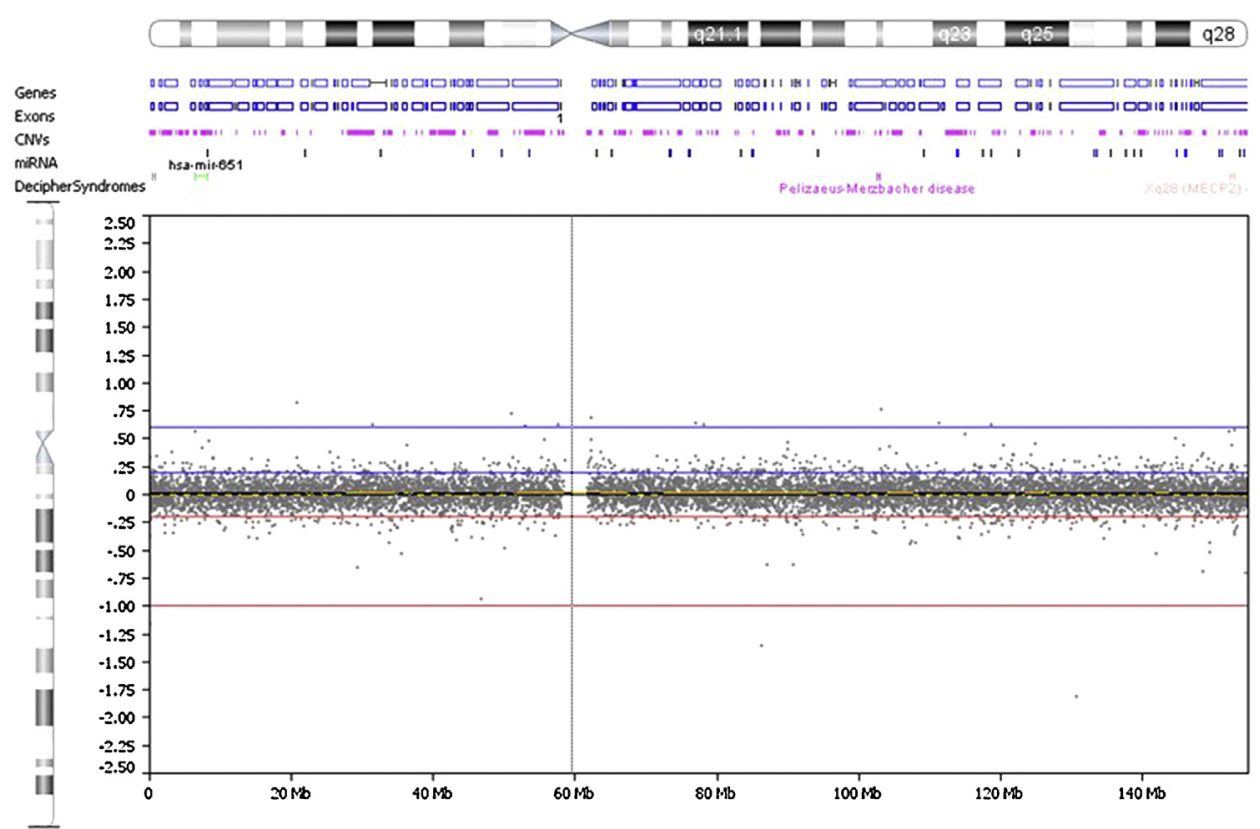

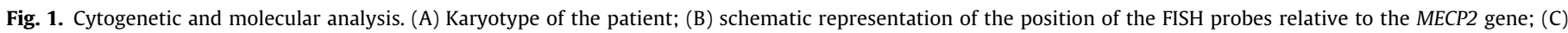

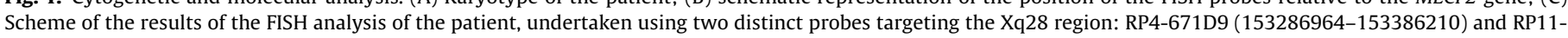

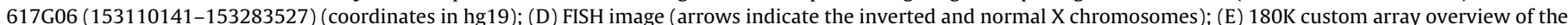
$\mathrm{X}$ chromosome showing absence of CNVs.

methylation at the assessed CpG site (Fig. 2C), a pattern that is likely associated with the increased MECP2 gene expression observed in lymphocytes, and which we speculate may also be happening in the nervous system. These findings lead us to speculate that MECP2 overexpression is the most likely disease causing mechanism in this patient.

\section{Discussion}

Rett syndrome (RTT) results in a large fraction of patients (more than $90 \%$ ) from mutations in the MECP2 gene in patients that fulfill the diagnostic criteria and, in lesser frequency, in patients with socalled variant forms of the disease, that do not comply with all 


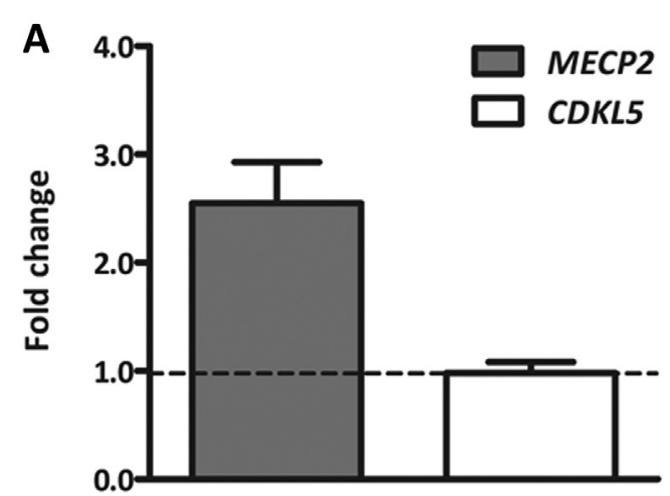

C

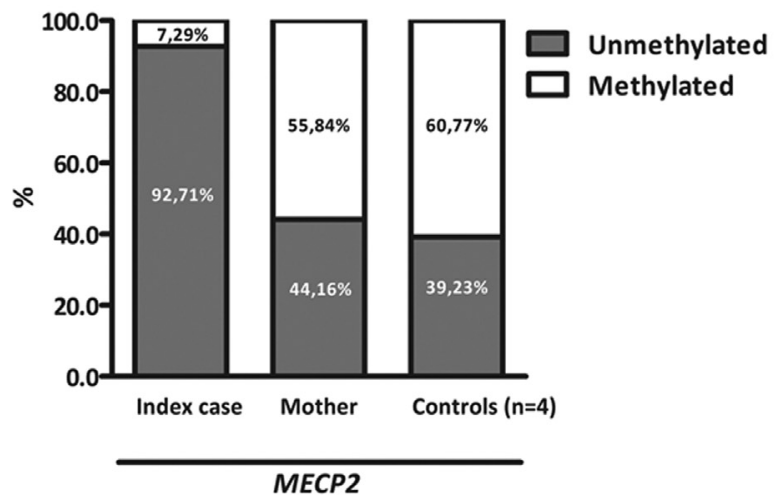

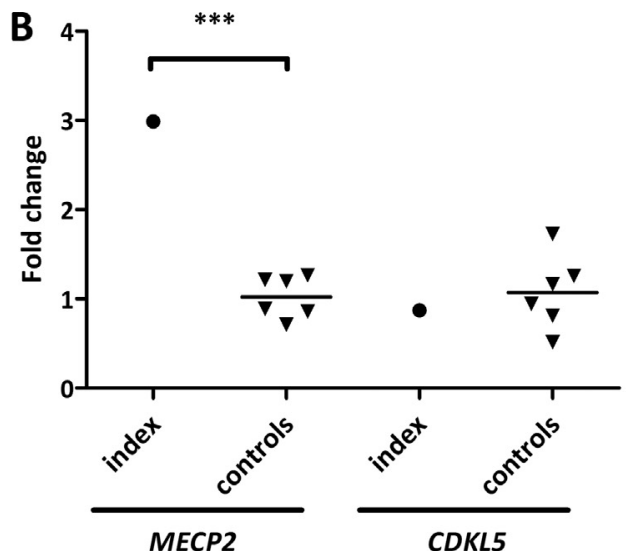

D

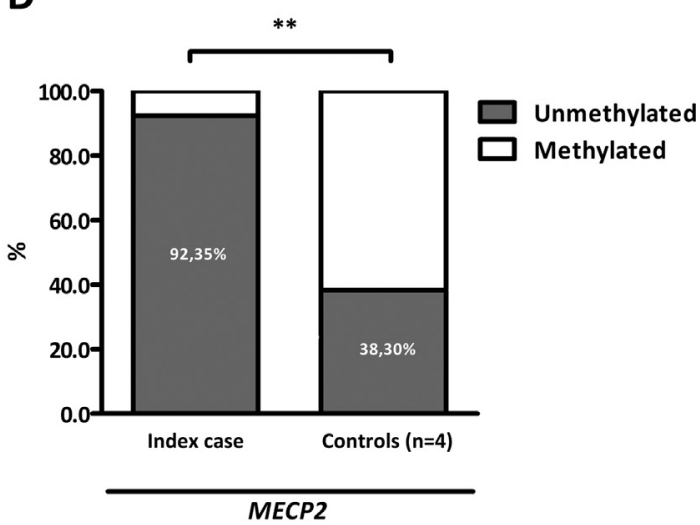

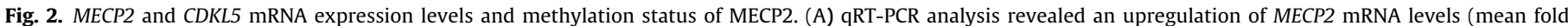

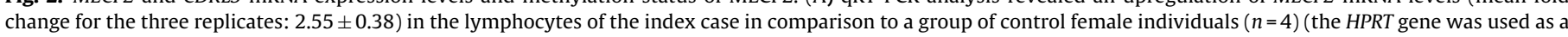

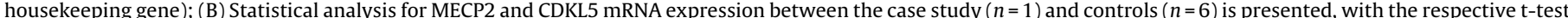

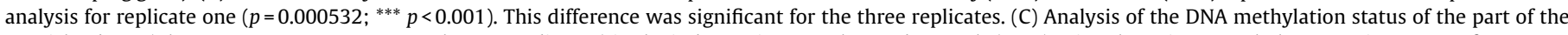

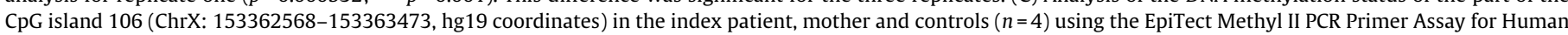

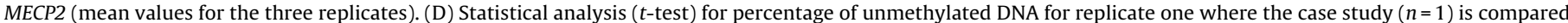
with the controls $(n=4)\left(p=0.002152 ;{ }^{* *} p<0.05\right)$. This difference was significant for the three replicates.

these criteria (Amir et al., 1999; Hoffbuhr et al., 2001; Philippe et al., 2006).

Although our patient does not meet the diagnostic criteria for classic RTT (because she fulfills only two of the four major criteria), her development was normal in the first months of life and later a severe retardation emerged, she has acquired microcephaly, neurologic signs in lower limbs, cold and pale feet, scoliosis, bruxism and, importantly, a persistent and prolonged history of RTT-like hand stereotypies, which are among the most striking clinical features of RTT. With this combination of signs and symptoms she also does not strictly meet diagnostic criteria for variant RTT as published in 2001 (Hagberg et al., 2002) or, more recently, in 2010 (Neul et al., 2010); she does, however, meet the criteria for variant RTT according to the early Hagberg classification (Hagberg and Skjeldal, 1994). The main difference between later and former diagnostic criteria is that the 2001 and 2010 criteria emphasize regression (which is questionable in this case) as a key diagnostic feature of RTT. Therefore, and given this phenotypic resemblance, we were encouraged to study the MECP2 gene.

Although the MECP2 gene itself was not mutated nor involved in the chromosomal rearrangement, its expression was altered, and this deregulation might underlie the neurodevelopmental phenotype observed. This phenotype differs from that of male patients with MECP2 duplications (Van Esch, 2012). Heterozygous females with MECP2 duplication usually show extreme to complete skewing of X-chromosome inactivation and are asymptomatic or have mainly neuropsychiatric disorders, but severe mental retardation has been reported (Bijlsma et al., 2012). We were not able to determine the mechanism through which the pericentric inversion is affecting the methylation and the transcriptional regulation of the MECP2 gene. aCGH analysis, provided no evidence for deletions or duplications encompassing other genes described as mutated in RTT-like phenotypes or a known or suspected regulatory element that could be related with MECP2 altered expression. Taking these findings in consideration, we hypothesize that the structural alteration of the $\mathrm{X}$ chromosome, even without significantly large CNVs, could be disrupting chromosomal domain organization and long-range genomic interactions (Maksimenko and Georgiev, 2014; Robyr et al., 2011), thus influencing MECP2 epigenetic modifications, including DNA methylation, and consequently modifying its expression. This type of perturbation has been described in fibroblasts of patients with Down syndrome (Letourneau et al., 2014).

In summary, we report the case of a girl with a Rett syndromelike clinical presentation with a pericentric inversion in the $\mathrm{X}$ chromosome $46, \mathrm{X}, \operatorname{inv}(\mathrm{X})(\mathrm{p} 22.1 \mathrm{q} 28)$ that doesnit disrupt the MECP2 gene but is accompanied by epigenetic changes in the form of decreased DNA methylation levels within the $5^{\prime}$ regulatory region of $M E C P 2$ gene, leading to a significantly increased expression of the gene. We speculate that this de-regulation of $M E C P 2$ expression may be a novel mechanism underlying disease in other RTT-like patients who test negative for MECP2 mutations, a hypothesis that should be investigated in the near future. 


\section{Acknowledgments}

We thank the patient and family for their participation, all the members of the Microarray Core Facility, Cancer Center Amsterdam at Vrije Universiteit Medical Center for technical help with the array design and CGC Genetics/Centro de Genética Clínica S.A. for karyotype and FISH analysis.

\section{References}

Amir, R.E., Van den Veyver, I.B., Wan, M., Tran, C.Q., Francke, U., Zoghbi, H.Y., 1999. Rett syndrome is caused by mutations in X-linked MECP2: encoding methyl-CpG-binding protein 2. Nat. Genet. 23, 185-188.

Ariani, F., Mari, F., Pescucci, C., Longo, I., Bruttini, M., Meloni, I., Hayek, G., Rocchi, R. Zappella, M., Renieri, A., 2004. Real-time quantitative PCR as a routine method for screening large rearrangements in Rett syndrome: report of one case of MECP2 deletion and one case of MECP2 duplication. Hum. Mutat. 24, 172-177.

Bijlsma, E.K., Collins, A., Papa, F.T., Tejada, M.I., Wheeler, P., Peeters, E.a.J., Gijsbers, A.C.J., van de Kamp, J.M., Kriek, M., Losekoot, M., Broekma, A.J., Crolla, J.A. Pollazzon, M., Mucciolo, M., Katzaki, E., Disciglio, V., Ferreri, M.I., Marozza, A., Mencarelli, M.A., Castagnini, C., Dosa, L., Ariani, F., Mari, F., Canitano, R., Hayek, G., Botella, M.P., Gener, B., Mínguez, M., Renieri, A., Ruivenkamp, C.a.L., 2012 Xq28 duplications including MECP2 in five females: expanding the phenotype to severe mental retardation. Eur. J. Med. Genet. 55, 404-413.

Buffart, T.E., Israeli, D., Tijssen, M., Vosse, S.J., Mrsić, A., Meijer, G.A., Ylstra, B., 2008. Across array comparative genomic hybridization: a strategy to reduce reference channel hybridizations. Genes Chromosomes Cancer 47, 994-1004.

Collins, A.L., Levenson, J.M., Vilaythong, A.P., Richman, R., Armstrong, D.L., Noebels, J.L., David Sweatt, J., Zoghbi, H.Y., 2004. Mild overexpression of MeCP2 causes a progressive neurological disorder in mice. Hum. Mol. Genet. 13, 2679-2689.

Hagberg, B., Aicardi, J., Dias, K., Ramos, O., 1983. A progressive syndrome of autism, dementia, ataxia, and loss of purposeful hand use in girls: Rett's syndrome: report of 35 cases. Ann. Neurol. 14, 471-479.

Hagberg, B.A., Skjeldal, O.H., 1994. Rett variants: a suggested model for inclusion criteria. Pediatr. Neurol. 11, 5-11.

Hagberg, B., Hanefeld, F., Percy, A., Skjeldal, O., 2002. An update on clinically applicable diagnostic criteria in Rett syndrome Comments to Rett Syndrome Clinical Criteria Consensus Panel Satellite to European Paediatric Neurology Society Meeting, Baden Baden, Germany, 11 September 2001. Eur. J. Paediatr. Neurol. EJPN Off. J. Eur. Paediatr. Neurol. Soc. 6, 293-297.

Hoebeeck, J., van der Luijt, R., Poppe, B., De Smet, E., Yigit, N., Claes, K., Zewald, R., de, J., ong, G.-J., De Paepe, A., Speleman, F., Vandesompele, J., 2005. Rapid detection of VHL exon deletions using real-time quantitative PCR. Lab. Investig. J. Tech. Methods Pathol. 85, 24-33.

Hoffbuhr, K., Devaney, J.M., LaFleur, B., Sirianni, N., Scacheri, C., Giron, J., Schuette, J., Innis, J., Marino, M., Philippart, M., Narayanan, V., Umansky, R., Kronn, D.,
Hoffman, E.P., Naidu, S., 2001. MeCP2 mutations in children with and without the phenotype of Rett syndrome. Neurology 56, 1486-1495.

Jovanovic, L., Delahunt, B., McIver, B., Eberhardt, N.L., Grebe, S.K.G., 2003. Optimising restriction enzyme cleavage of DNA derived from archiva histopathological samples: an improved HUMARA assay. Pathology (Phila.) 35, 70-74.

Letourneau, A., Santoni, F.A., Bonilla, X., Sailani, M.R., Gonzalez, D., Kind, J., Chevalier, C., Thurman, R., Sandstrom, R.S., Hibaoui, Y., Garieri, M., Popadin, K., Falconnet, E., Gagnebin, M., Gehrig, C., Vannier, A., Guipponi, M., Farinelli, L., Robyr, D., Migliavacca, E., Borel, C., Deutsch, S., Feki, A., Stamatoyannopoulos, J.A., Herault, Y., van Steensel, B., Guigo, R., Antonarakis, S.E., 2014. Domains of genome-wide gene expression dysregulation in Down's syndrome. Nature 508, 345-350.

Makrythanasis, P., Moix, I., Gimelli, S., Fluss, J., Aliferis, K., Antonarakis, S.E., Morris, M.A., Béna, F., Bottani, A., 2010. De novo duplication of MECP2 in a girl with mental retardation and no obvious dysmorphic features. Clin. Genet. 78, $175-180$.

Maksimenko, O., Georgiev, P., 2014. Mechanisms and proteins involved in long-distance interactions. Front. Genet. 5, 28.

Neul, J.L., Kaufmann, W.E., Glaze, D.G., Christodoulou, J., Clarke, A.J., Bahi-Buisson, N., Leonard, H., Bailey, M.E.S., Schanen, N.C., Zappella, M., Renieri, A., Huppke, P., Percy, A.K., RettSearch, C., onsortium, 2010. Rett syndrome: revised diagnostic criteria and nomenclature. Ann. Neurol. 68, 944-950.

Pfaffl, M.W., 2001. A new mathematical model for relative quantification in real-time RT-PCR. Nucleic Acids Res. 29, e45.

Philippe, C., Villard, L., De Roux, N., Raynaud, M., Bonnefond, J.P., Pasquier, L., Lesca, G., Mancini, J., Jonveaux, P., Moncla, A., Chelly, J., Bienvenu, T., 2006. Spectrum and distribution of MECP2 mutations in 424 Rett syndrome patients: a molecular update. Eur. J. Med. Genet. 49, 9-18.

Ramocki, M.B., Peters, S.U., Tavyev, Y.J., Zhang, F., Carvalho, C.M.B., Schaaf, C.P., Richman, R., Fang, P., Glaze, D.G., Lupski, J.R., Zoghbi, H.Y., 2009. Autism and other neuropsychiatric symptoms are prevalent in individuals with MeCP2 duplication syndrome. Ann. Neurol. 66, 771-782.

Rett, A., 1966. On a unusual brain atrophy syndrome in hyperammonemia in childhood. Wien. Med. Wochenschr. 1946 (116), 723-726.

Robyr, D., Friedli, M., Gehrig, C., Arcangeli, M., Marin, M., Guipponi, M., Farinelli, L., Barde, I., Verp, S., Trono, D., Antonarakis, S.E., 2011. Chromosome conformation capture uncovers potential genome-wide interactions between human conserved non-coding sequences. PloS One 6, e17634.

Van Esch, H., 2012. MECP2 duplication syndrome. Mol. Syndromol. 2, 128-136.

Van Esch, H., Bauters, M., Ignatius, J., Jansen, M., Raynaud, M., Hollanders, K., Lugtenberg, D., Bienvenu, T., Jensen, L.R., Gecz, J., Moraine, C., Marynen, P., Fryns, J.-P., Froyen, G., 2005. Duplication of the MECP2 region is a frequent cause of severe mental retardation and progressive neurological symptoms in males. Am. J. Hum. Genet. 77, 442-453. 